\title{
THE ENCHANTING OF INFORMATION SYSTEMS WITH Digital TECHNOLOGIES
}

\author{
Zeljko Stojkic, Igor Bosnjak \& Luka Saravanja
}
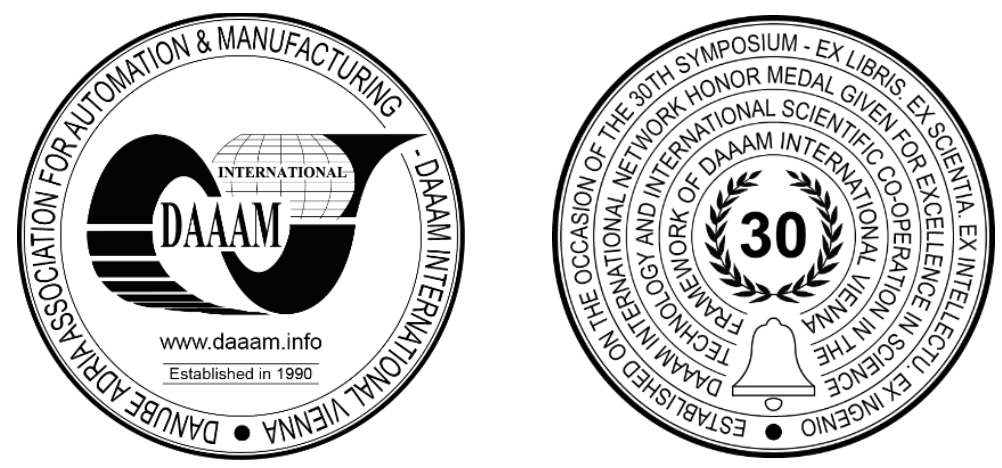

This Publication has to be referred as: Stojkic, Z[eljko]; Saravanja, L[uka] \& Bosnjak, I[gor] (2020). The Enchanting of Information Systems with Digital Technologies, Proceedings of the 31st DAAAM International Symposium, pp.0771-0779, B. Katalinic (Ed.), Published by DAAAM International, ISBN 978-3-902734-29-7, ISSN 1726-9679, Vienna, Austria

DOI: $10.2507 / 31$ st.daaam.proceedings. 107

\begin{abstract}
Today's production requirements, such as shorter lead times, higher quality, and at the same time, lower prices push companies to the limits. In order to overcome these problems and to be able to respond to user requirements, it is necessary to create a working environment, which will be characterized by a high degree of flexibility. One of the most important steps towards achieving balanced and flexible production is the application of digital technologies and organizational tools. The aim of this paper is to contribute to a better understanding of the possibilities of digital technologies in the field of information systems in production. Also, the goal is to offer manufacturing companies possible solutions to overcome obstacles on the way to digitalization and Industry 4.0. This paper will present an example of process optimization by using digital technologies. Also, an overview of the literature in the field of information systems improvement by means of digital technologies will be presented throughout the paper. It will also describe the current state of information systems (ERP systems) within SMEs and possible steps towards the optimization of production processes using digitalization. Finally, the measurement and evaluation of the efficiency of one part of the production process according to three different models will be presented.
\end{abstract}

Keywords: Information systems; ERP; digital technologies; tracking technology; mobile application

\section{Introduction}

In the condition of global competition on the market, companies can achieve a competitive advantage only by offering cheaper and better products and services. To achieve these goals, companies need effective and innovative business processes. Also, it should be emphasized that partial business changes are not enough to achieve this goal. Intensive, continuous and robust changes in the company's business have to be conducted. These changes will have, as a result, lower expenditures, and shorter production cycles [1]. Changes are aimed at reshaping, restructuring, and innovating business processes through the application of information and digitalization technologies. Also, today's production model, such as smaller series and a more comprehensive range of products and services with emphasized personalized and individualized characteristics, require from companies to make complete and continuous changes in business processes and the entire business. 
In addition to changes in business processes, companies need to focus their efforts on the development of information technology and the introduction of a new or improvement of an existing information system. Therefore, the paper will review the work in the field of information systems with particular stress to ERP systems. In this paper, modern digital technologies, which represent great support to information systems and production management, will be described. In the first place, these are tracking technologies, i.e. Auto-ID technology such as Barcode, QR code, and RFID (Radio Frequency Identification). The main advantages of these technologies such as wide application, automatization, reliability, transparency and safety, make them one of the most important in the field of monitoring and information collecting. Also, the paper will cover mobile applications, software for smartphones and other mobile devices. Its essential feature makes information systems mobile, i.e. faster and more flexible collection and processing of information. In the end, a case study will be conducted at the Learning Factory, where the efficiencies of the production process will be measured and evaluated according to three different models. The first model represents the realization of the production process without any information system. The second model represents the realization of the production process with an ERP system, and the third model represents enchantment of ERP system with new technologies such as tracking technology (barcode, QRCode, and RFID) and a mobile application.

The purpose of the case study is to show the advantages of digital technologies application in manufacturing information systems $t$ and to offer manufacturing companies possible solutions and ways to overcome obstacles on the road to Industry 4.0 .

\section{Information systems - literature review}

An information system is a formal part of a communication system of a certain business unit. It consists of a group of people and machines that process information and use it or enter into communication links to achieve business or service process goals [2]. Another definition: Information Systems (IS) are social systems that deal with the interaction of people and technology. An information system, including an Enterprise Resource Planning (ERP) system, is userinterface and designed to provide information useful to support strategy, operations, management analysis, and decision-making functions in an organization [3]. According to the above definitions, it could be concluded that information systems (IS) are complex systems, whose interpretation and data processing significantly affect business decisions and shape the company's strategy. Therefore, the success of the implementation and exploitation of such systems largely determines the success of the company itself. IS consists of people, equipment, technology, and procedures that enable the collection, storage, analysis, processing, and distribution of data and information to users and business decision-makers [1].

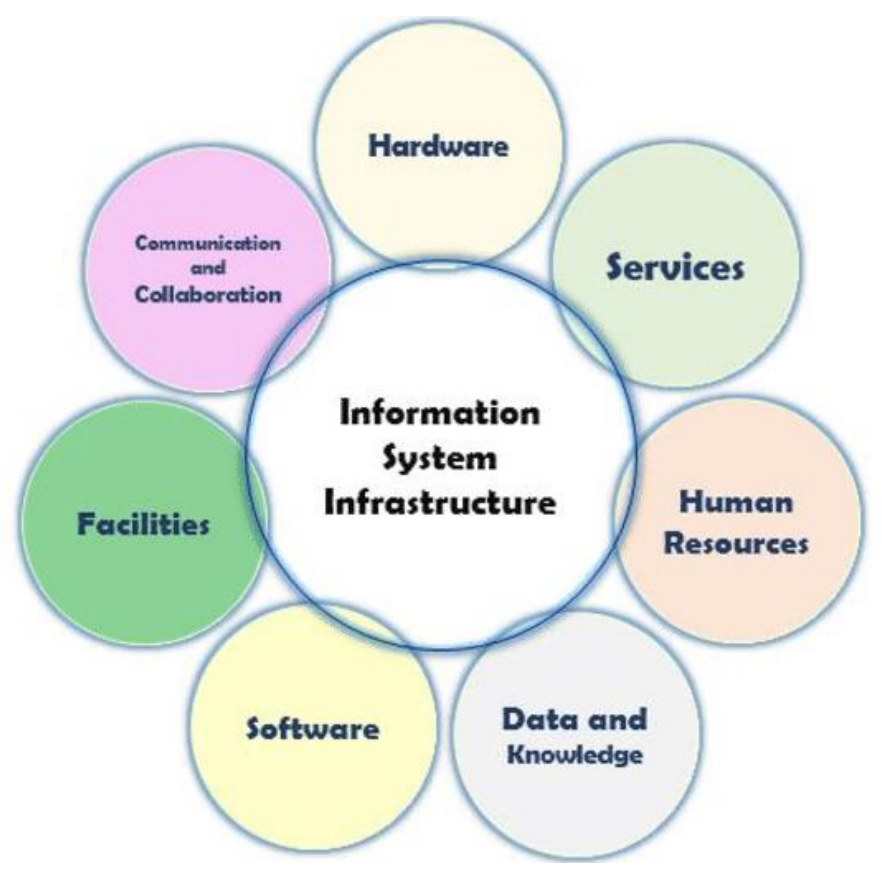

Fig. 1. Information system infrastructure

There are many advantages of using information systems, such as faster decision making, greater management control, cost reduction, etc. Especially nowadays, when timely and accurate information is a strategic advantage over the competition, it makes such a system indispensable in running a business. However, the proper implementation of such systems requires radical changes in the organization, high financial investments, and a long period of implementation, in the form of reengineering the business processes of the company. 
Due to high costs and significant organizational changes, until today, the implementation of information systems has mostly been reserved only for large companies. But lately, information system vendors have been making great efforts to tailor their products and solutions to small and medium-sized businesses. In the following, the most essential information systems such as ERP (Enterprise Resource Planning), CRM (Customer Relationship Management), and MES (Manufacturing Execution System) will be briefly discussed.

The term ERP system means an integrated software solution that is built based on standardized modules and supports a significant part of the business processes from a business, economic and information aspect. The system set up in this way, based on the entered and processed data, offers up-to-date information on the state of the system, enabling planning, management, and control [1]. In ERP systems, the decision-making process is centralized and located at the highest level of the automation pyramid (Fig. 2).

The second level in the traditional automation pyramid is the Manufacturing Execution System (MES) (Fig 2.). It supports production reporting, scheduling, dispatching, product tracking, maintenance operations, performance analysis, workforce tracking, resource allocation and similar. It covers aspects such as management of the shop floor and communication with the enterprise (business) systems. Most of the software solutions available on the market are centralized and not distributed to the shop floor elements. That is a major limiting factor when flexibility is needed due to the dynamics of customers' order flow and changing production environment, including shop floor configuration [4].

CRM is an information system whose primary goal is to collect information about customers, which would be used to increase customer satisfaction and commitment, in order to have better, longer, and more profitable relationships with customers [5].

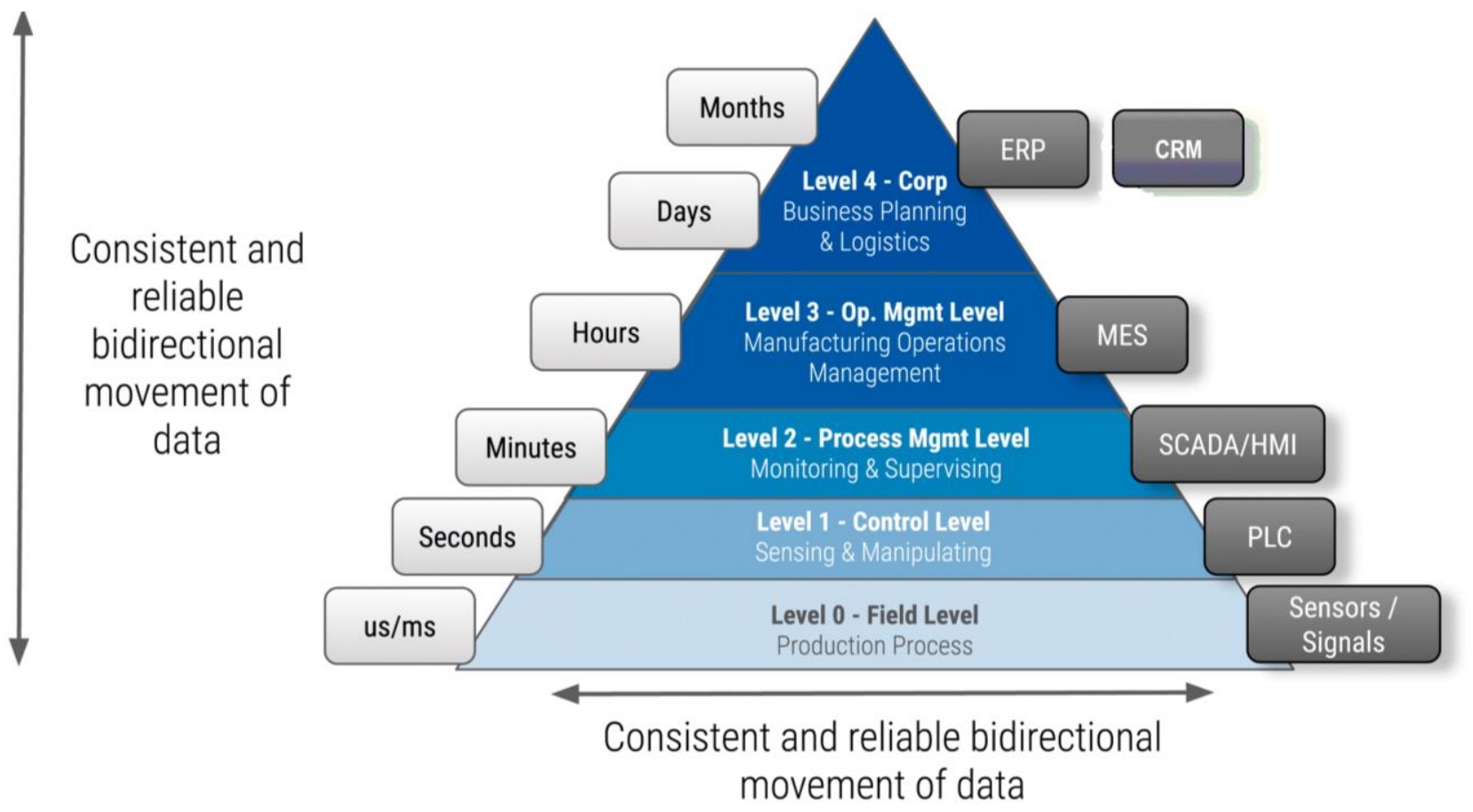

Fig. 2. Automation pyramid in modern production systems

According to the above, it can be concluded that information systems represent the "nervous system" of manufacturing companies, whose proper and detailed implementation plays a crucial role in adapting companies to increasingly complex and demanding markets. In this area, managers are making the most significant efforts to maximize and exploit the potentials of manufacturing companies. Optimization of information systems is a delicate and comprehensive task that entails great responsibility and high investment of time and money, all to improve production efficiency. The most common activities in this area are the integration of information systems (e.g. integration of ERP and CRM systems) and integration of information systems with digital technologies, such as tracking technologies and mobile applications, which will be discussed below.

All of these activities represent steps on the road to Industry 4.0. According to GTAI 2014 [6] Smart industry or "Industrie 4.0" refers to the technological evolution from embedded systems to cyber-physical systems. "Industrie 4.0" represents the coming fourth industrial revolution on the way to an Internet of Things, Data, and Services. Decentralized intelligence helps create an intelligent object by networking and independent process management. It is achieved with the interaction of the real and virtual worlds representing a crucial new aspect of the manufacturing and production process. Industrie 4.0 represents a paradigm shift from "centralized" to "decentralized" production - made possible by technological advances that constitute a reversal of conventional production process logic. 
This means that industrial production machinery no longer only "processes" the product, but that the product communicates with the machinery to tell it exactly what to do. Therefore, Industry 4.0. promotes the integration of new digital technologies into production processes, enables the reduction of production costs, improves the response to customer requirements, enables customized mass production without higher production costs, a more flexible and friendly working environment. According to some sources, Industry 4.0. enables the reduction of production costs by $10-30 \%$, reduction of logistics costs by $10-30 \%$, and reduction of management costs by $10-20 \%$ [4].

\section{Current state of information systems in our region}

In our region, the use of digital technologies in information systems is just in the beginning. The concept of Industry 4.0 , which represents the use of modern solutions in the field of digitization, is not yet sufficiently recognized as a concept that offers continuous progress and survival of companies in the global market. Still, great efforts are being made to change that as well. Thus, the INSENT [7] (Innovative Smart Enterprises) project was done in the neighbouring Republic of Croatia, whose primary goal was to develop the Croatian model of Innovative Smart Enterprise. As part of the INSENT project, an analysis of the current situation of Croatian and Bosnian and Herzegovinian industrial companies was performed. In order to analyze the current situation, a questionnaire was created, on which 161 companies responded. The questionnaire consisted of 9 basic questions, which related to the activity of business processes from product development, through production planning and quality assurance. For each of these questions, the respondent is allowed to determine the industry level from 1.0 to 4.0. within the surveyed company. According to the results of the survey, the industrial maturity index of Croatian companies is 2.15 , which is a very low level. Given that the questionnaire was completed by a large number of companies, which in the Republic of Croatia and Bosnia and Herzegovina are at the highest level of industrial maturity, it can be concluded that the average maturity index of companies is even lower than stated. Also, through the INSENT project, an analysis of the application of information and communication technologies (ICT) was conducted. Through questionnaire and company visits, a detailed analysis of the maturity of information and communication technologies (ICT) and the application of software solutions in business processes was made. The main conclusions of the analysis are the following:

- Business processes and information systems (ERP /PLM). During a detailed analysis in companies, it was found that there are no standardized acceptable business practices for managing different forms of items in information systems (raw material, semi-finished product, product, fixed asset, etc.) and that in practice there is a need for a higher level of accounting and better ERP solutions.

- (Non) integration of information solutions. In a large number of companies, the integration of systems/solutions is not performed well, which negatively affects the entire business process. As a typical example of a business process that has a separate, non-integrated solution is the quality assurance

- Integration of ERP and CAD systems. The insufficient connection between design and production processes is observed. There are few companies where direct electronic communication between CAD and ERP solutions is achieved.

- Use of MS Excel. MS Excel is often used as a planning tool (sometimes as the only one, and sometimes as a tool for correcting annual and monthly plans made in ERP) and reporting at all levels in companies. More advanced analytical reporting systems were not mentioned during the company visits.

- Electronic business. Exchange of documents with partners via the Internet is mainly reduced to inquiries, offers, price lists, and orders in PDF and XLS (Excel) format via email. In contrast, the direct electronic exchange of documents between information systems is very rare.

- Cloud computing. Mostly everyone uses mail services in the public cloud. Also, in business, a large number of companies use cloud solutions in addition to traditional solutions. Regarding business applications, which are located in these clouds, it should be noted that these are mostly older applications that are hosted most often on a local server or a server in a remote central location of the company.

- System integration at the production plant level (MES- Manufacturing Execution System). Direct communication between ERP systems and machines in the production plant is at a very low level (plan - work order - records reports). Even in companies that monitor the production plant in great detail and where the machines are equipped with software to monitor individual operations, specialized software is not integrated with planning software (ERP or other specialized software).

In conclusion, the detailed analysis confirmed the preliminary opinion on a relatively low level of ICT application in manufacturing companies. Here it is important to emphasize that ICT is one of the foundations of the new technological era and that without significant investment in this fundamental segment of technology it will not be possible to reach the era of smart products that communicate. As already pointed out, Industry 4.0 means connecting work staff, equipment and products, therefore, modern information systems are needed that will be able to connect them into one whole and enable faster, more intuitive, and flexible decision-making. Modernization of information systems, as one of the prerequisites for Industry 4.0, is reflected in the integration of information systems, the use of digital technologies such as tracking and Auto-ID technologies, and mobile applications that will enable mobility and accessibility of information systems. 


\section{Digital technologies as ERP support on the way to industry 4.0}

Enterprise Resource Planning (ERP) systems integrate all information and processes of an organization into a merged system that concerns how people and organizations access, collect, store, gather, summarize, interpret and use information. An ERP system integrates different components of computer software and hardware to enable information flow throughout the enterprise. An important element of most ERP systems is the use of a unified database to gather data for the different system modules. ERP technology is complex, and its implementation often entails significant risks. Despite these risks, organizations implement ERP systems for greater visibility into the business process [8]. The ERP system itself evolved from the MRP II (Manufacturing Resource Planning) concept, which followed the MRP (Material Requirements Planning) concept. MRP observed only material needs based on supply and demand and components in production. MRP II represents the management of production resources and integrates. In addition to the MRP, production resources, procurement, and sales ensure monitoring of the situation and comparisons actuallyplanned. The emergence of ERP stands for Enriched MRP II and additionally includes profitability monitoring, quality assurance, technical maintenance, logistics and distribution, service activities as well as human resource management.

The goal of these systems is to capture an increasing amount of information useful for business improvement, i.e. for faster and more dynamic decision-making and business strategy [1]. Also, the process of system integration and development continues today. The integration of partner companies and suppliers SCM (Supply Chain Management concept) and customer CRM (Customer Relationship Management) into the company's internal information system has already been practically realized. The next step of integration is often defined in the literature as an ERP II system. In order to have integrated and highly complex information systems, which functions well with each other, it is required to have access to relevant and fresh data collected and processed through business processes. With the help of digital technologies, it is possible to monitor, collect, process, and use data. Primarily we mean on tracking technology for data collection and processing and mobile applications as new paradigms in production management processes.

\subsection{The role of tracking technologies in enhancing ERP system}

Typical challenges that manufacturing enterprises are facing now are compounded by a lack of timely, accurate, and consistent information about manufacturing resources on the shop floor. As a result, it becomes difficult to introduce and implement advanced manufacturing technologies and strategies [9]. Recent developments in wireless sensors, communication, and information technologies (e.g. radio frequency identification - RFID or Auto-ID, Bluetooth, Wi-Fi, etc.) and the application of well-established identification technologies, such as barcode and QR code, has enabled a new era of information collection and management. New models of automatic data collection and monitoring reduce the time to make quality decisions, reduce the likelihood of error and eliminate, most often tiring, repetitive, manual work of data collection and processing. Tracking and Auto-ID technologies will be discussed in detail below.

"Traceability" is a term often used as synonymous of tracking, and is defined as "the ability to trace the history, application or location of that which is under consideration", which is related to the International Standard Organization definition "ability to trace the history, application or location of an entity by means of recorded identifications" (ISO 8402) [10]. These definitions can let envisage the system's primary function to provide visibility and traceability. Therefore, a tracking system is an information system that captures current and past information on location, status, physical integrity, environment conditions, identity, or life cycle of moving objects. When this identification takes place in an automated way to provide tracking or tracing information, then it is understood as an Auto-ID system. This information could be used for collaborative decision-making processes or some other types of managerial or administrative processes. A tracking system is, in simple words, a supplier of such information [10]. Therefore, they are indispensable in modern information systems such as ERP, wherewith mobile applications they make it faster, more flexible, and more accessible. In the continuation of the chapter, the most important and most common tracking technologies, such as Barcode, QRcode and RFID, will be discussed. Barcode is a linear binary code formed by lines and spaces (white lines) of varying thicknesses printed in different combinations. Since it is a visual data collection technology, a visual interaction of the reader and the label with the code is required. Barcode has a wide range of applications and today is one of the most common tracking technologies. Also, today's wireless barcode scanners allow remote data collection, making it a very convenient option when tracking inventory in warehouses or when logging in or out of work orders. QR (Quick Response) code is a type of matrix bar code or two-dimensional code that can store data information and is designed to be read by smartphones. QR stands for "Quick Response" indicating that the code contents should be decoded very quickly at high speed. The code consists of black modules arranged in a square pattern on a white background. The information encoded may be text, a URL, or other data. The popularity of QR codes is growing rapidly all around the world. Nowadays, mobile phones with built-in cameras are widely used to recognize the QR Codes [11]. The very first concept of the QR code was developed at Toyota's Denso subsidiary, and the main reason for this is the limited information capacity of the barcode (it can only contain 20 alphanumeric characters). As a technology developed for the tracking of automotive parts, today it is applied in many other areas, such as commercial tracking, product labelling in stores, entertainment, etc. The basic elements of a QR code system are an encoder and a decoder. The encoder is in charge of encoding the data and generating the QR code, while the decoder decodes the data. Since only a smartphone is needed to read the QR code, which we all mostly have with us, the QR code is very suitable for tracking and collecting information on stocks in warehouses, as well as for logging in and out of work orders. 
RFID (Radio Frequency Identification) belongs to the group of technologies with automatic identification (AutoID), i.e. it is used to identify and track objects and has a wide application in various industries, including manufacturing. Auto-ID technology is a new way of controlling and collecting information and is suitable for more complex production networks. RFID is a wireless contactless radio system, which transmits data from an RFID tag attached to an object, to identify and track it. RFID systems can be classified by the working frequency, i.e., low frequency (LF), high frequency (HF), ultra-high frequency (UHF), and microwave. Different frequencies work for various media, e.g., UHF is not applicable to metal, but HF is metal friendly. Thus, the working frequency has to be determined based on the tracked objects. Hardware for an RFID system includes an RFID tag, an RFID reader, and an RFID antenna. The RFID tag is an electronic device that can store and transmit data to a reader in a contactless manner using radio waves, which can be read-only or read-written. Tag memory can be factory programmed or later on the field. It can also be partitionable, and optionally permanently locked, which enables the users to save customized information in the tag and read it everywhere, or retire the tag when it is not used anymore. Bytes left unlocked can be rewritten over more than 100,000 times, which results in a longer useful life. Moreover, the tags can be classified by power methods, i.e., passive tags without power, semi-passive tags with battery, and active tags with battery, processor, and I/O ports [12].

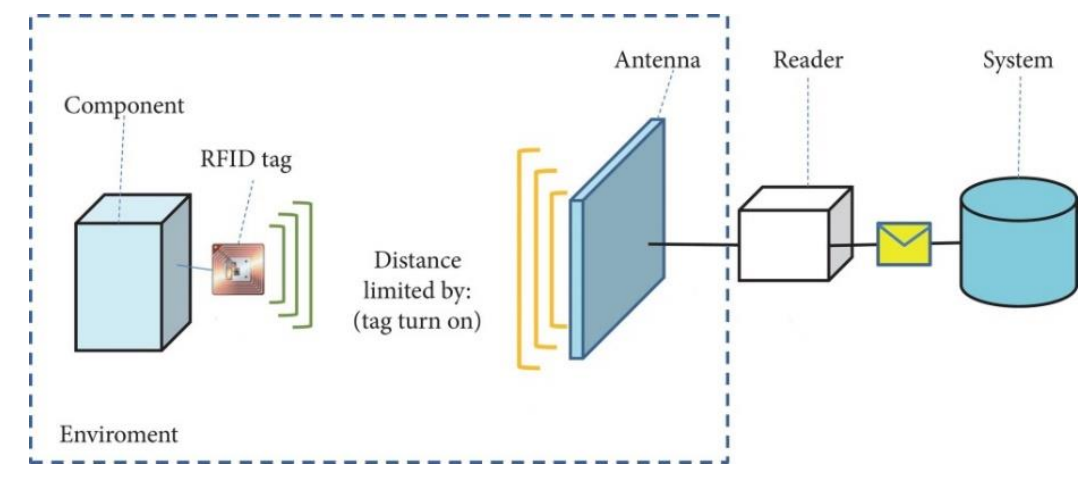

Fig. 3. A typical RFID system

With its characteristics and advantages, RFID technology plays a significant role in the concept of the Internet of Things (IoT) and Industry 4.0. Although RFID was initially developed for tracking and identification purposes, growing interest in many other possible applications has led to the development of a new range of wireless sensor devices based on RFID. In many cases, the automatic and continuous sensing capabilities of RFID can eliminate the need for human labour in the data collection process and enable more automated factories [13]. In recent years, several leading vehicle manufacturers employed radio frequency identification (RFID) to facilitate manufacturing shop-floor management. As early as 2000, Volvo Trucks had established an RFID system on the detail racks in its paint shops to achieve continuous production notwithstanding communication loss. BMW, since 2003, has set up four RFID-based real-time location systems within four German plants, where active tags are deployed on finished vehicles. Toyota has implemented information systems based on RFID to track auto parts production in French and South African facilities [14]. With the increasing application of this technology, especially in today's age of digitalization, there are demands for increased security of these systems, such as privacy protection and business process protection. Although this technology has been used successfully in the industrial sector for many years, its development is still ongoing.

\subsection{Mobile application}

Manufacturing companies often manage production by conducting fieldwork, operations research, or by monitoring product/ service delivery to ensure efficient production operations. To acquire relevant feedback, decision-makers, senior operations managers, and field workers need accurate and timely data, enabling rapid decision-making in the event of any interruptions in production. Therefore, data collection is a key component in ensuring the success of production management. However, most data collection systems are heavily reliant on paper forms, resulting in high costs, questionable accuracy, and long turnaround times [15]. From a business perspective, new business models are needed, which will increase profitability, improve the position to the competition, and attract new customers. In the time of digitalization and widespread use of mobile devices (smartphones), a logical solution appears for the need to integrate mobile technologies with existing information systems, i.e. use of mobile applications (mobile devices) in data collection and business process management. Nowadays, smartphones have become powerful programmable mobile devices with built-in multifunction sensors, which can support different types of data (text messages, images, videos, GPS data, bar codes). It makes them a good platform for development, implementation, and use of mobile applications. The use of mobile applications significantly reduces the need to fill out paper forms during production, which shortens the time of data collection and entry; data is timely and accurate. For example, manually collecting and entering data into information systems would, in most cases, be entered by workers at the end of a shift. Several hundred papers would be fed into systems such as ERP every day, and it took several hours. At the same time, the current use of mobile applications can significantly reduce the time required to enter data. 
Integration with ERP system

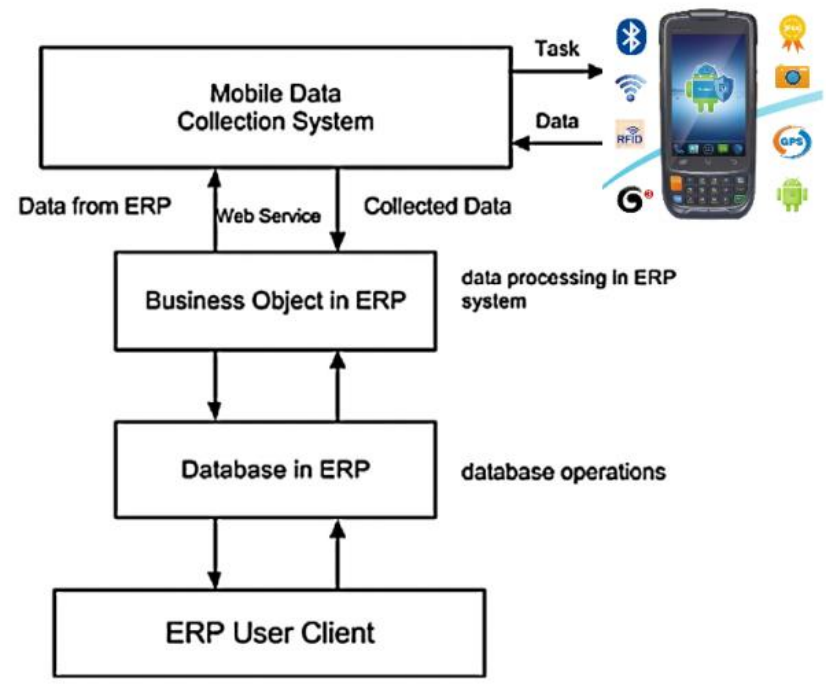

Fig. 4. Transfer data from the mobile system to a legacy system

In the Learning Factory, at the University of Mostar, the faculty team has developed a mobile application that is directly connected to the ERP system database. With the help of the mobile application, it is possible to perform all important activities in production, such as $\log$ in and log out of work orders, material requirements planning, review of master data, and many other activities. Also, the mobile application is connected to an RFID industrial printer, which allows the printing of labels (bar code, QR code, or an RFID tag) in production directly from the mobile application.
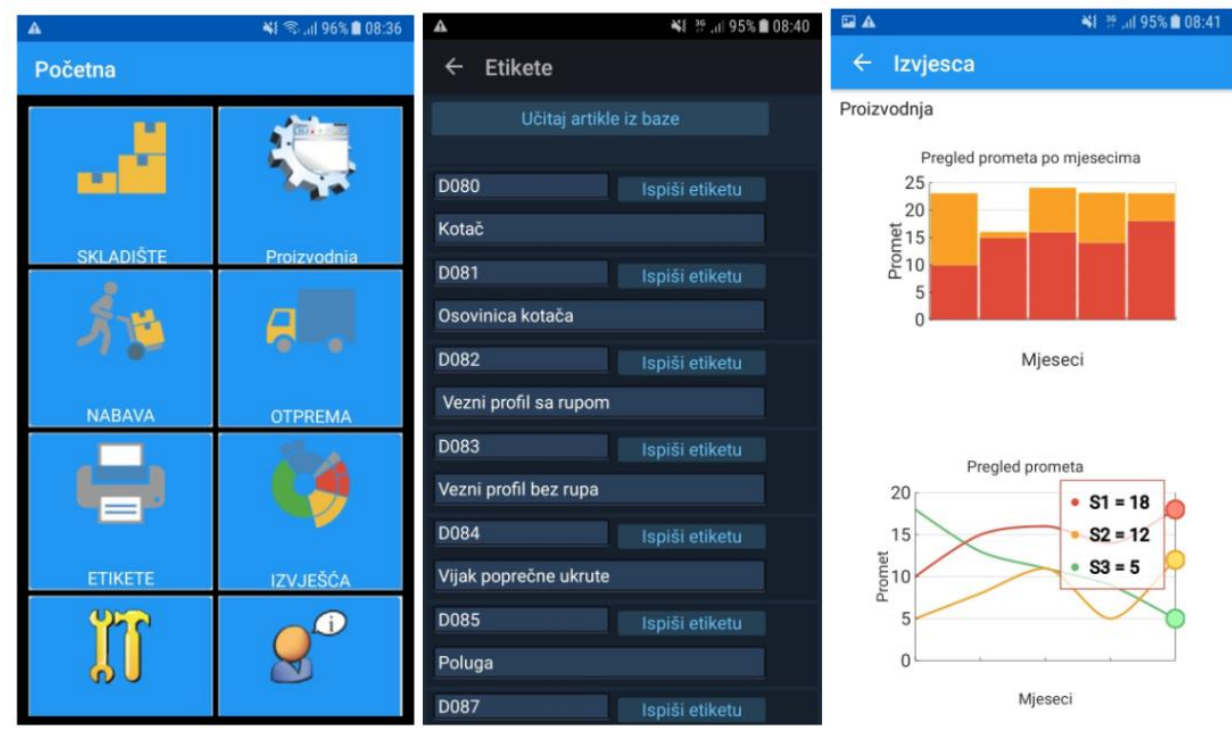

Fig. 5. Mobile application interface developed at the Learning Factory, University of Mostar

\section{Case study}

The case study was conducted within the Learning Factory, University of Mostar. The study aims to check and prove the improvement of information systems by applying digital technologies in the form of optimization and shortening the time of information flow. The case study was designed in three models. The first and basic model is a model in which the flow of information goes with the help of paper forms, which are filled in manually. The reason for choosing an already outdated model as a starting point lies in the fact that a large number of companies in our environment work according to this principle. The second model involves the use of an ERP system, while the third model includes ERP software and mobile or desktop applications. To evaluate these three models, we selected the material restock process and the login and logout of production order operations. Due to the similarity of the obtained results in both processes, only the restock process will be presented in more detail in the paper, Table 1. 


\begin{tabular}{|l|l|l|l|}
\hline $\begin{array}{l}\text { I. model } \\
\text { (paper form) }\end{array}$ & $\begin{array}{l}\text { Filling out a } \\
\text { restock order }\end{array}$ \\
\hline $\begin{array}{l}\text { II. model } \\
\text { system) }\end{array}$ & $\begin{array}{l}\text { Restock order } \\
\text { generated in } \\
\text { ERP system }\end{array}$ \\
$\begin{array}{l}\text { III. model } \\
\text { (ERP system } \\
\text { and mobile } \\
\text { app. }\end{array}$ & $\begin{array}{l}\text { Restock order } \\
\text { generated in ERP } \\
\text { system }\end{array}$ & $\begin{array}{l}\text { Information } \\
\text { returns via }\end{array}$ \\
\hline
\end{tabular}

Table 1. Restorage process procedure according to three models

\begin{tabular}{|c|c|c|c|}
\hline & I model & II model & III model \\
\hline Information flow time & $5 \mathrm{~min} 50 \mathrm{sec}$ & $1 \mathrm{~min} 40 \mathrm{sec}$ & $40 \mathrm{sec}$ \\
\hline $\begin{array}{l}\text { Amount of information } \\
\text { (complete and concise) } 1 \text { - } \\
5 \text { ( } 1 \text { poor, } 5 \text { excellent) }\end{array}$ & 3 & 5 & 5 \\
\hline $\begin{array}{l}\text { Quality of information } \\
\text { (accuracy, } \\
\text { timeliness, } \\
\text { availability) } 1-5 \\
\text { poor, 5 excellent }\end{array}$ & 2 & 4 & 5 \\
\hline Comments & $\begin{array}{l}\text { (due to the large number of } \\
\text { paper forms and waiting } \\
\text { within the process, the } \\
\text { availability and accuracy of } \\
\text { information is mostly } \\
\text { reduced) }\end{array}$ & $\begin{array}{l}\text { (a very good source of } \\
\text { information, which is not } \\
\text { always available due to } \\
\text { administrative problems, } \\
\text { waiting within the process) }\end{array}$ & $\begin{array}{l}\text { (an excellent source of } \\
\text { information, which } \\
\text { implies a high degree of } \\
\text { accurate and accessible } \\
\text { information) }\end{array}$ \\
\hline
\end{tabular}

Table 2. Results of the performed time measurement of the model and the estimated quality and quantity of information

Based on the obtained results, it can be concluded that there are significant time savings when using ERP software solutions and that these times can be further reduced by applying digital technologies that allow flexibility, mobility, and faster information flow. Model I, due to the large number of paper forms, which are often inaccessible, make this model worse than the other two models. The other two models provide complete and concise information. Due to administrative problems, i.e. waits until the return of information from production, model II. (ERP systems) often have inaccessible and inaccurate information. Therefore, the overall quality of information is significantly higher in III. model, due to the "mobile" character, which allows the availability of relevant and recent information from anywhere inside and outside the company.

\section{Conclusion}

We can conclude that in today's information age, in a time where accurate and timely information is a competitive advantage, the implementation and use of information systems seem indispensable in running business processes. Proper implementation and exploitation of information systems is the key to the success of sustainable and profitable business management. The main disadvantage of such systems is the excessive administrative procedure for collecting information within production, which ultimately results in unreliable and inaccessible data within information systems. In order to overcome these obstacles, the information systems are undergoing a kind of transformation, digital technologies such as tracking technologies and the use of mobile applications are being introduced into the systems, which significantly contribute to the flexibility and overall improvement of information systems. Although digital technologies and information systems themselves bring several advantages, they are still underrepresented in our region, which results in significant difficulties in placing products on the market. Therefore, great efforts are needed from company managers and all stakeholders to take significant steps to increase the maturity and readiness of companies to new technologies, which will enable competitiveness in the market. In the end, we can only conclude that the information system with the help of digitalization and mutual integration enable companies to survive in an uncertain market. Therefore, future research will be focused on further increasing the efficiency of business processes through the integration of information systems and further use and connection of digital technologies 


\section{References}

[1] Stojkic, Z. (2008). Utjecaj stupnja razvijenosti integriranih informacijskih sustava na kvalitetu poslovnih procesa, The impact of the degree of development of integrated information systems on the quality of business processes, Ph.D. Dissertation, Faculty of mechanical engineering and computing, University of Mostar, Mostar, Bosnia and Herzegovina

[2] Simovic, V. (2009). Uvod u informacijske sustave, Introduction to information systems, Golden marketing Tehnička knjiga, ISBN 978-953-212-354-8, Zagreb, Croatia

[3] Matande, U. \& Ogao, P. (2013). Enterprise resource planning (ERP) system implementation: A case for user participation, CENTERIS 2013 - Conference of ENTERprise Information Systems / PRojMAN 2013 International Conference of Project MANagement / HCIST 2013 - International Conference on Health and social care information Systems and Technologies, Procedia Technology Vol. 9, 2013, pp. 518-526., DOI: 10.1016/j.protcy.2013.12.058

[4] Rojko, A. (2017). Industry 4.0 Concept: Background and overview, international Journal of Interactive Mobile Technologies (iJIM) Vol. 11, No 5, eISSN: 1865-7923

[5] Stojkic, Z.; Veza, I. \& Bosnjak, I. (2016). A concept of information system implementation (CRM and ERP) within industry 4.0, Proceedings of the 26th DAAAM International Symposium (pp. 0912-0919), B. Katalinic (Ed.), Published by DAAAM International, ISBN 978-3-902734-07-5, ISSN1726-9679, Vienna, Austria DOI: $10.2507 / 26$ th.daaam.proceedings. 127

[6] Germany Trade and Invest, (2014). Industry 4.0 Smart manufacturing for the future, https://www.manufacturingpolicy.eng.cam.ac.uk/documents-folder/policies/germany-industrie-4-0-smart-manufacturing-for-the-futuregtai/view

[7] Veza, I. et al. (2018). Inoativno pametno poduzeće, An innovative smart enterprise, ISBN 978-953-290-082-8, University of Split

[8] Malhotra, R. \& Temponi, C. (2010). Critical decisions for ERP integration: Small business issues, International Journal of Information Management, Vol.30, 2010, pp. 28-37, DOI: 10.1016/j.ijinfomgt.2009.03.001

[9] Li, H.; Sun, S. \& Zhang, Y. (2012). Using auto-ID technologies to implement real-time manufacturing resources tracking and tracing, Applied Mechanics and Materials, Vol. 121- 126, 2012, pp. 1574 -1578, DOI: 10.4028/www.scientific.net/AMM.121-126.1574

[10] Monsreal, M.; Dai,H.; Tseng, M. \& Brock, D. (2011). Tracking technologies in supply chains, In: Wiley Encyclopedia of Operations Research and Management Science, DOI: 10.1002/9780470400531.eorms0995

[11] Tiwari, S. (2016). An introduction to QR code technology, 2016 International Conference on Information Technology, DOI: 10.1109/ICIT.2016.021

[12] Wang, K. S. (2014). Intelligent and integrated RFID (II-RFID) system for improving traceability in manufacturing, Advances in Manufacturing, Vol. 2, 2014, pp. 106-120, DOI: 10.1007/s40436-014-0053-6

[13] Xu, L.D.; Xu, L.E. \& Li, L. (2018). Industry 4.0: state of the art and future trends, International Journal of Production Research, Vol. 56, No. 8, pp. 2941-2962., ISSN 0020-7543, DOI: 10.1080/00207543.2018.1444806

[14] Dai, Q.et al. (2011). Radio frequency identification-enabled real-time manufacturing execution system: a case study in an automotive part manufacturer, International Journal of Computer Integrated Manufacturing, Vol. 25, No. 1, 2012, pp. 51-65., DOI: 10.1080/0951192X.2011.562546

[15] Park, J. (2015). Evaluating a mobile data-collection system for production information in SMEs, Computers in Industry, Vol. 68, 2015, pp. 53-64., DOI: 10.1016/j.compind.2014.12.006 